\title{
Phase I study of sunitinib plus S-1 and cisplatin in Japanese patients with advanced or metastatic gastric cancer
}

\author{
Narikazu Boku • Kei Muro • Nozomu Machida • \\ Satoshi Hashigaki • Nobuyuki Kimura • Mie Suzuki • \\ Mariajose Lechuga • Yoshinori Miyata
}

Received: 28 November 2012 / Accepted: 1 March 2013 / Published online: 12 May 2013

(C) The Author(s) 2013. This article is published with open access at Springerlink.com

\begin{abstract}
Summary Background This phase I, dose-finding study evaluated the maximum tolerated dose (MTD), safety, pharmacokinetics, and antitumor activity of sunitinib plus S-1/cisplatin in Japanese patients with advanced/metastatic gastric cancer. Patients and methods Patients received oral sunitinib on a continuous daily dosing (CDD) or 2-weeks-on/2-weeksoff schedule (Schedule $2 / 2 ; 25 \mathrm{mg} /$ day or $37.5 \mathrm{mg}$ /day), plus S-1 $(80-120 \mathrm{mg} /$ day $) /$ cisplatin $60 \mathrm{mg} / \mathrm{m}^{2}$. Results Twenty-
\end{abstract}

Presented in part on the clinical trial registry located at ClinicalTrials.gov (identification No. NCT00553696) and at:

N. Boku $(\bowtie)$

Department of Clinical Oncology, St. Marianna University School of Medicine, 2-16-1, Sugao, Miyamae-ku,

Kawasaki, Kanagawa 216-8511, Japan

e-mail: n.boku@marianna-u.ac.jp

K. Muro

Department of Clinical Oncology, Aichi Cancer Center, Nagoya, Japan

N. Machida

Division of Gastrointestinal Oncology, Shizuoka Cancer Center,

Shizuoka, Japan

S. Hashigaki

Clinical Statistics, Pfizer Japan, Tokyo, Japan

N. Kimura

Clinical Pharmacology, Pfizer Japan, Tokyo, Japan

M. Suzuki

Clinical Research, Pfizer Japan, Tokyo, Japan

M. Lechuga

Pfizer Oncology, Pfizer Italia Srl, Latina, Italy

Y. Miyata

Department of Oncology, Saku Central Hospital, Saku, Japan seven patients received treatment, including 26 patients treated per protocol (sunitinib $25 \mathrm{mg} /$ day CDD schedule, $n=4$; sunitinib $25 \mathrm{mg} /$ day Schedule $2 / 2, n=16$ [dose-limiting toxicity (DLT) cohort, $n=6$ plus expansion cohort, $n=$ 10]; sunitinib $37.5 \mathrm{mg} /$ day Schedule $2 / 2, n=6$ ). One patient erroneously self-administered sunitinib $12.5 \mathrm{mg} /$ day and was excluded from the analyses. The MTD was sunitinib $25 \mathrm{mg} /$ day on Schedule 2/2. DLTs were reported for: $2 / 4$ patients given sunitinib $25 \mathrm{mg}$ /day on the CDD schedule; $1 / 6$ patients administered sunitinib $25 \mathrm{mg}$ /day on Schedule 2/2 (grade [G] 3 neutropenic infection, G4 thrombocytopenia, and S-1 dose interruption $\geq 5$ days), and $3 / 6$ patients given sunitinib $37.5 \mathrm{mg}$ /day on Schedule 2/2. Results below are for the overall MTD cohort $(n=16)$. The most frequently reported G3/4 adverse events were neutropenia $(93.8 \%)$ and leukopenia $(75.0 \%)$. The objective response rate was $37.5 \%$; six additional patients experienced no disease progression for $\geq 24$ weeks. Median progression-free survival was 12.5 months. No pharmacokinetic drug-drug interactions were observed between sunitinib/S-1/cisplatin and S-1/cisplatin. Conclusions The MTD of sunitinib was $25 \mathrm{mg}$ /day on Schedule 2/2 combined with cisplatin/S-1 in patients with advanced/metastatic gastric cancer. This regimen had a manageable safety profile and preliminary antitumor activity.

Keywords Sunitinib · Gastric cancer · Phase I · Dose-finding

\section{Introduction}

Gastric cancer is the second most common cause of cancerrelated death worldwide, with more than 730,000 deaths estimated to have occurred in 2008 [1]. Globally, the 
5 -year survival rate for gastric cancer is approximately $20 \%$ [2], and most patients present with advanced, non-resectable disease [3-5].

Despite recent advances in the treatment for gastric cancer [6], a standard chemotherapy regimen has not been established for recurrent or unresectable advanced gastric cancer; combination chemotherapy is associated with significant survival and quality of life advantages, compared with best supportive care [7, 8]. The use of a 5-fluorouracil (5-FU)based regimen in combination with a platinum analog is the most widely accepted first-line treatment regimen, although combination therapy does have a higher associated toxicity burden compared with single-agent chemotherapy [8].

Blockade of receptors such as vascular endothelial growth factor receptor (VEGFR) and platelet-derived growth factor receptor (PDGFR) has been shown to inhibit tumor-related angiogenesis and tumor growth $[9,10]$. Not only are these receptors expressed in gastric cancers but they are known to have direct effects on the growth and metastasis of this disease [9-14].

Sunitinib malate (SUTENT ${ }^{\circledR}$; Pfizer Inc., New York, NY, USA) is an oral, multitargeted, tyrosine kinase inhibitor of VEGFRs $1-3$, PDGFR- $\alpha$ and $-\beta$, and other receptors [15-17]. Sunitinib is approved multinationally for the treatment of unresectable and/or metastatic imatinib-resistant/-intolerant gastrointestinal stromal tumor, advanced/metastatic renal cell carcinoma, and unresectable or metastatic, well-differentiated pancreatic neuroendocrine tumors. Phase II study results in advanced gastric cancer have shown that sunitinib had activity as a single-agent; progression-free survival (PFS) was 2.3 months and overall survival was 6.8 months in the second-line setting [18].

In preclinical tumor models, sunitinib has been shown to enhance the antitumor activity of 5-FU and cisplatin, suggesting that sunitinib might enhance the effect of chemotherapy in cancer patients $[19,20]$. In the First-Line Advanced Gastric Cancer Study (FLAGS), the combination of S-1, an oral derivative of 5-FU, and cisplatin was found to be effective when administered as a 3-week on/1-week off regimen (Schedule 3/1) [21]. Therefore, this phase I, dose-finding study was conducted to determine the maximum tolerated dose (MTD) and overall safety profile of sunitinib plus S-1 and cisplatin in Japanese patients with advanced/metastatic gastric cancer. Tolerability, pharmacokinetics (PK), and antitumor activity were also evaluated.

\section{Materials and methods}

Study population

Patients (male or female) eligible for inclusion in this study were aged $\geq 20$ years, had an Eastern Cooperative Oncology
Group performance status of 0 or 1 , adequate organ function, and histologically or cytologically confirmed Stage IV gastric adenocarcinoma or gastroesophageal junction adenocarcinoma not amenable to surgery or radiation. Prior adjuvant therapy was permitted with a recurrence-free interval of $>3$ months after the completion of adjuvant therapy. Prior chemotherapy in the advanced/metastatic setting was not permitted; one regimen of chemotherapy, such as S-1 monotherapy, without progressive disease was allowed if the duration of treatment was less than 4 weeks.

Exclusion criteria included central nervous system (CNS) metastases, carcinomatous meningitis, or uncontrolled hypertension (blood pressure $>150 / 100 \mathrm{mmHg}$ ). Patients with severe/unstable angina, myocardial infarction, coronary artery bypass graft, symptomatic congestive heart failure, cerebrovascular accident, including transient ischemic attack, or pulmonary embolism within 12 months prior to starting study treatment were also excluded.

The study was conducted in accordance with the International Conference on Harmonization Good Clinical Practice guidelines, the declaration of Helsinki, and applicable local regulatory requirements and laws. Approval from the institutional review board or independent ethics committee with the appropriate jurisdiction was required for each participating investigator/center. Written informed consent was obtained from all patients.

\section{Study design}

This was a phase I, open-label, dose-finding study of sunitinib in combination with $\mathrm{S}-1$ and cisplatin in patients with advanced/metastatic gastric cancer (NCT00553696). Patients received open-label, oral S-1 at a starting dose of 80 $120 \mathrm{mg} /$ day (based on body surface area) on Schedule 3/1 and a cisplatin $60 \mathrm{mg} / \mathrm{m}^{2}$ infusion on day 1 that was repeated every 28 days. Patients were allocated to different doses of oral sunitinib based on a $3+3$ design. Initially, sunitinib was planned to be administered on a continuous daily dosing (CDD) schedule or on Schedule 3/1. After four patients received treatment in the CDD arm, the protocol was revised to use a 2-week-on/2-week-off schedule (Schedule 2/2), instead of Schedule 3/1, due to the pattern of adverse events (AEs). Patients received sunitinib $25 \mathrm{mg} /$ day on a CDD schedule, or $25 \mathrm{mg} /$ day or $37.5 \mathrm{mg} /$ day on Schedule $2 / 2 \mathrm{in}$ 4-weekcycles (Fig. 1).

Initially, three patients were enrolled to receive sunitinib $25 \mathrm{mg} /$ day on the CDD schedule in combination with S-1 and cisplatin $60 \mathrm{mg} / \mathrm{m}^{2}$. If no patients experienced a doselimiting toxicity (DLT) in cycle 1 then patients would be enrolled to the next highest dose level. If no more than one of the initial three patients experienced a DLT within cycle 1 , then the cohort was expanded to a total of six patients. If no more than one of these six patients experienced a DLT, 
Fig. 1 Treatment schema.

${ }^{\text {a }}$ Sunitinib dose withheld on cycle 1 day 1 to enable pharmacokinetic analysis of S-1 and cisplatin. ${ }^{\mathrm{b}} \mathrm{S}-1$ and cisplatin dose withheld on cycle 1 day 1 to enable pharmacokinetic analysis of sunitinib. BID twice daily; Schedule 2/2 2 weeks on treatment followed by 2 weeks off treatment

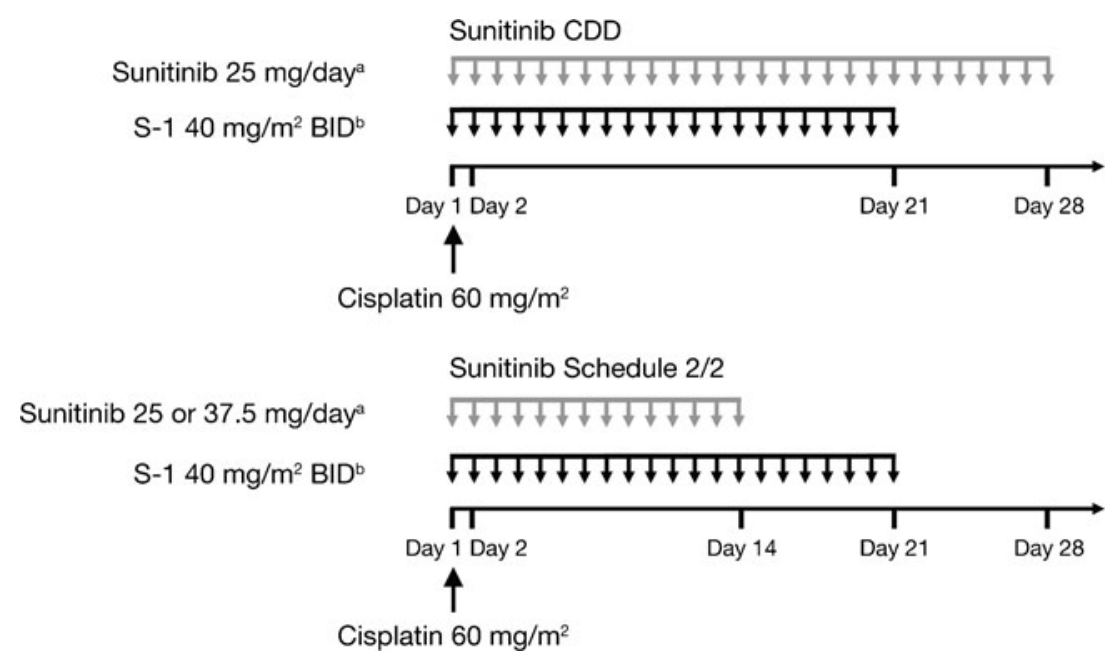

then patients would be enrolled at the next highest dose level.

The MTD was defined as the highest dose cohort where $0 / 3$ or $\leq 1 / 6$ patients experienced a DLT, with the next highest dose having at least $2 / 3$ or $2 / 6$ patients who experienced a DLT. DLTs are defined in Table 1 . In this study, the MTD level was confirmed by expanding enrollment to include up to 10 additional patients with advanced/metastatic disease in order to obtain additional safety data for the combination treatment. It was anticipated that a total of approximately 30 patients would be enrolled in this study.

Dose modifications of sunitinib were not allowed until a DLT was reached. Once dose reduction occurred due to study drug-related toxicity, the dose was not re-escalated. Patients could undergo a maximum of two dose reductions of either S-1 and/or cisplatin. However, patients requiring more than two dose reductions of S-1 or sunitinib were withdrawn from the study. Additionally, patients with $>1$ missed cisplatin dose were withdrawn. Treatment was continued for 8 cycles or until disease progression, unacceptable toxicity, or withdrawal of patient consent.

The primary endpoint was the assessment of first-cycle DLTs for sunitinib plus S-1 and cisplatin. Secondary endpoints included overall safety, tumor response, PFS, and PK.

\section{Assessments}

Patients were evaluable for DLT assessment if they received all day 1 chemotherapy and $\geq 80 \%$ of their sunitinib doses and S- 1 doses. Those who could not receive $\geq 80 \%$ of their doses for reasons other than a DLT were excluded from the DLT evaluation. Tumor assessment was performed at baseline, on day 22 of cycle 1, and every 4 weeks thereafter until radiographic-confirmed disease progression or end of treatment scan. Objective tumor response in patients with at least one target lesion was measured using the Response Evaluation Criteria in Solid Tumors (RECIST) guidelines [22]

Table 1 Definition of DLT

\begin{tabular}{ll}
\hline Category & DLT criteria \\
\hline Hematologic & Grade 4 neutropenia lasting $\geq 7$ days \\
& Grade $\geq 3$ febrile neutropenia \\
& Grade $\geq 3$ neutropenic infection \\
& Grade 4 thrombocytopenia or grade 3 thrombocytopenia with bleeding \\
& Grade 3 toxicities lasting $\geq 7$ days \\
Non-hematologic & Grade 4 non-hematologic toxicity \\
& Grade $3 / 4$ nausea, vomiting or diarrhea persisting despite maximum supportive therapy \\
& Break from sunitinib dose $\geq 6 / 28$ days on the CDD schedule or $\geq 3 / 14$ days on Schedule $2 / 2$ \\
Missed/delayed dose due to toxicity & Break from $S-1$ dose $\geq 5 / 21$ days per cycle \\
& Delay of $>3$ weeks in starting the second treatment cycle
\end{tabular}

$C D D$ continuous daily dosing; DLT dose-limiting toxicity; Schedule 2/2 2 weeks on treatment followed by 2 weeks off treatment

${ }^{a}$ Exceptions: hyperamylasemia or hyperlipasemia without other clinical evidence of pancreatitis and asymptomatic hyperuricemia; asymptomatic hypertension with adequately controlled blood pressure 
and confirmed no sooner than 4 weeks after the initial documentation of response.

Safety was assessed at regular intervals (during cycle 1 on days $1,2,8,15$, and 22 ; during cycles $2-8$ on days 1,2 , and 21; and during cycles $\geq 9$ on days 1 and 21). AEs were monitored during the study and graded using the National Cancer Institute Common Terminology for Adverse Events version 3.0 clinical assessments, including laboratory testing for blood hematology and serum chemistry.

To investigate PK drug-drug interactions, full PK profiles of sunitinib, its active metabolite SU12662, S-1 (5-FU, tegafur) and cisplatin (total and free) were assessed in all cohorts comprising the $3+3$ design, and in the MTD expansion cohort. Blood samples for analyses of cisplatin and S-1 were collected on cycle 1 days 1-2 (S-1 and cisplatin), before starting sunitinib dosing on day 2 , and on cycle 2 days 1-2 (in combination with sunitinib) in the MTD cohort. In the expansion cohort, blood samples for the analyses of sunitinib and SU12662 were collected on cycle 1 days 1-2 (sunitinib alone), prior to administration of S-1 and cisplatin on day 2, and cycle 2 days 1-2 (in combination with S-1 and cisplatin). PK parameters were calculated using noncompartmental methods.

Trough plasma concentrations of sunitinib and SU12662 were obtained at steady state on cycles 1-3 days 21-22 for the CDD schedule, and cycles 1-3 days $14-15$ for Schedule $2 / 2$. Blood samples were obtained before the administration of sunitinib and S-1.

On the day of cisplatin PK sampling, blood was drawn pre-dose (before administration of cisplatin, S-1 or sunitinib) and at $0.5,1,2,8$, and $22 \mathrm{~h}$ after completing infusion. Samples for evaluation of sunitinib, SU12662, and S-1 PK were obtained pre-dose (before administration of either S-1 or sunitinib) and at 1, 2, 4, 6, 8, and $10 \mathrm{~h}$ postdose (before dosing of S-1). For sunitinib and SU12662, a sample was also obtained $24 \mathrm{~h}$ post-dose.

Plasma samples were analyzed for sunitinib and SU12662 concentrations by Bioanalytical Systems Inc. (USA) using a validated high-performance liquid chromatography tandem mass spectrometric (HPLC-MS/MS) method. Tegafur and 5-FU plasma concentrations were also determined using a validated HPLC-MS/MS method by Tandem Labs (USA). Cisplatin concentrations were determined in both plasma and plasma ultra filtrate samples by Covance Laboratories Inc. (USA) using a validated Inductively Coupled Plasma-Mass Spectrometric (ICP/MS) method.

\section{Statistical analysis}

The sample size was determined on an empirical rather than statistical basis. Assessment of 3-6 patients for each cohort was considered adequate to characterize the safety of a treatment regimen prior to investigation in phase II clinical trials. It was anticipated that up to 30 patients would be enrolled in this study.

Efficacy analyses included all patients who received at least one protocol-specified dose of sunitinib. Descriptive statistics were used to summarize all patient characteristics, treatment administration/compliance, antitumor activity, and safety; PFS was summarized using the Kaplan-Meier method. In an unplanned exploratory analysis, clinical benefit rate (CBR; percentage of patients with a complete response, partial response, and stable disease $\geq 24$ weeks) and PFS were calculated in patients with scirrhous-type disease of primary tumors.

\section{Results}

\section{Patient characteristics}

In total, 27 patients received treatment, including 26 patients treated per protocol (sunitinib $25 \mathrm{mg} /$ day on the CDD schedule, 4; sunitinib $25 \mathrm{mg} /$ day on Schedule $2 / 2$, 16 [DLT cohort, 6 plus expansion cohort, 10]; sunitinib $37.5 \mathrm{mg} /$ day on Schedule 2/2, 6), and one patient who was assigned to sunitinib $25 \mathrm{mg}$ /day on Schedule $2 / 2$ and erroneously self-administered sunitinib $12.5 \mathrm{mg}$ /day throughout the study. The latter patient was excluded from the efficacy analyses. One patient remained on study as of April 2012. Demographic and baseline disease characteristics are shown in Table 2. Overall, eight patients had scirrhous-type disease (seven patients in the MTD cohort).

\section{Safety and drug exposure}

Twenty-seven patients were evaluable for safety. The MTD was determined to be sunitinib $25 \mathrm{mg}$ /day on Schedule $2 / 2$ plus cisplatin and $\mathrm{S}-1$, and a further 10 patients were allocated to this cohort. Of the four patients who received sunitinib $25 \mathrm{mg} /$ day on the CDD schedule, two DLTs were reported: grade 4 thrombocytopenia $(n=1)$, and grade 4 thrombocytopenia plus grade 3 febrile neutropenia $(n=1)$. Subsequently, the treatment frequency was reduced to sunitinib $25 \mathrm{mg} /$ day on Schedule 2/2. In the second cohort, one of six patients reported a DLT: grade 3 neutropenic infection plus grade 4 thrombocytopenia and S- 1 dose interruption of $\geq 5$ days. As defined in the protocol, the sunitinib dose was then increased to $37.5 \mathrm{mg} /$ day on Schedule $2 / 2$, where three of six patients experienced a DLT: grade 3 febrile neutropenia plus S- 1 dose interruption of $\geq 5$ days $(n=1)$, grade 4 thrombocytopenia $(n=1)$, and grade 4 neutropenia of $\geq 7$ days $(n=1)$.

All patients experienced at least one AE. No grade 5 AEs occurred. Serious AEs (SAEs) were reported in 13 
Table 2 Baseline patient characteristics

\begin{tabular}{|c|c|c|c|c|}
\hline & \multirow{2}{*}{$\begin{array}{l}\text { CDD schedule sunitinib } 25 \mathrm{mg} / \text { day } \\
\text { All patients }(n=4)^{\mathrm{a}}\end{array}$} & \multicolumn{2}{|c|}{ Schedule $2 / 2$ sunitinib $25 \mathrm{mg}$ /day } & \multirow{2}{*}{$\begin{array}{l}\text { Schedule } 2 / 2 \text { sunitinib } \\
37.5 \mathrm{mg} / \text { day } \\
\text { All patients }(n=6)^{\mathrm{d}}\end{array}$} \\
\hline & & All patients $(n=16)^{\mathrm{b}, \mathrm{c}}$ & $\begin{array}{l}\text { Patients with scirrhous-type } \\
\text { disease }(n=7)\end{array}$ & \\
\hline Gender, male, $n(\%)$ & $2(50.0)$ & $13(81.3)$ & $6(85.7)$ & $4(66.7)$ \\
\hline \multicolumn{5}{|l|}{ Age, years } \\
\hline Median & 63.0 & 60.0 & 57.0 & 60.5 \\
\hline Range & $44-73$ & $31-71$ & $31-67$ & $28-71$ \\
\hline \multicolumn{5}{|c|}{ ECOG performance status, $n(\%)$} \\
\hline 0 & $1(25.0)$ & $7(43.8)$ & $2(28.6)$ & $3(50.0)$ \\
\hline 1 & $3(75.0)$ & $9(56.3)$ & $5(71.4)$ & $3(50.0)$ \\
\hline Measurable disease, $n(\%)$ & $3(75.0)$ & $11(68.8)$ & $5(71.4)$ & $4(66.7)$ \\
\hline \multicolumn{5}{|l|}{ Histology, $n(\%)$} \\
\hline Diffuse & $2(50.0)$ & $9(56.2)$ & $6(85.7)$ & $2(33.3)$ \\
\hline Intestinal & $2(50.0)$ & $7(43.8)$ & $1(14.3)$ & $3(50.0)$ \\
\hline Other & $0(0)$ & $0(0)$ & $0(0)$ & $1^{\mathrm{e}}(16.7)$ \\
\hline Prior surgery, $n(\%)$ & $1(25.0)$ & $5(31.3)$ & $1(14.3)$ & $2(33.3)$ \\
\hline \multicolumn{5}{|l|}{ Prior systemic therapy, $n(\%)$} \\
\hline 0 & $2(50.0)$ & $16(100.0)$ & $7(100.0)$ & $5(83.3)$ \\
\hline 1 & $2(50.0)$ & $0(0)$ & $0(0)$ & $1(16.7)$ \\
\hline$\geq 2$ & $0(0)$ & $0(0)$ & $0(0)$ & $0(0)$ \\
\hline
\end{tabular}

$C D D$ continuous daily dosing; ECOG Eastern Cooperative Oncology Group; Schedule 2/2 2 weeks on treatment followed by 2 weeks off treatment

${ }^{\text {a } I n c l u d e s}$ one patient with scirrhous-type disease

${ }^{\mathrm{b}}$ Includes 10 patients from the expansion cohort

${ }^{\mathrm{c}}$ The subject assigned to sunitinib $25 \mathrm{mg}$ /day on Schedule $2 / 2$ who mistakenly received sunitinib $12.5 \mathrm{mg} / \mathrm{day}$ was excluded from the efficacy analyses. At baseline, this patient had an ECOG performance status of 0, stage IV measurable intestinal disease, with 2 involved tumor sites (liver and lymph node) and no prior surgery or systemic therapy

${ }^{\mathrm{d}}$ No patients had scirrhous-type disease in this cohort

${ }^{\mathrm{e}}$ This patient had mucinous histology

patients overall $(48.1 \%)$. Dose reductions due to AEs occurred for all three drugs: sunitinib: $n=8$; S-1: $n=7$; cisplatin: $n=8$. At the MTD, the median relative dose intensity (\% actual/intended dose intensity) was $80.6 \%$ (range, 32.4-100.0) for sunitinib (25 mg/day, Schedule 2/2), 68.2\% (35.7-85.7) for S-1, and 73.8\% (27.1-98.9) for cisplatin. Overall, seven patients discontinued the study treatment due to AEs, including four patients in the MTD cohort.

In the MTD cohort (sunitinib $25 \mathrm{mg}$ /day, Schedule 2/2; $n=16$ ), the frequencies of common AEs of any grade are presented in Table 3. Neutropenia was the most frequently reported grade 3 or $4 \mathrm{AE}$, occurring in 15 patients $(93.8 \%)$. In total, $75.0 \%$ of patients in the MTD cohort experienced grade 3 or 4 leukopenia. Fatigue, decreased appetite, nausea, constipation, thrombocytopenia, and stomatitis were the most common grade 1 or 2 AEs reported. In this cohort, SAEs occurred in eight patients $(50.0 \%)$; the most frequent SAEs were febrile neutropenia $(n=3,18.8 \%)$ and platelet count decreased $(n=2,12.5 \%)$.

\section{Pharmacokinetics}

The MTD combination of sunitinib (25 mg/day, Schedule $2 / 2$ ) with S-1 plus cisplatin demonstrated no changes in the PK of sunitinib or its active metabolite (SU12662). In addition, combination treatment had no impact on the PK of cisplatin, tegafur, 5-FU, or S-1, compared with S-1 plus cisplatin alone (Table 4).

The mean trough plasma concentrations $\left(\mathrm{C}_{\text {trough }}\right)$ of sunitinib, SU12662, and total drug were $33.5 \mathrm{ng} / \mathrm{mL}$, $13.9 \mathrm{ng} / \mathrm{mL}$, and $47.5 \mathrm{ng} / \mathrm{mL}$, respectively, for sunitinib $25 \mathrm{mg} /$ day, and $69.9 \mathrm{ng} / \mathrm{mL}, 24.0 \mathrm{ng} / \mathrm{mL}$, and $93.4 \mathrm{ng} / \mathrm{mL}$, respectively, for sunitinib $37.5 \mathrm{mg} /$ day. These $C_{\text {trough values }}$ suggested that plasma concentrations of sunitinib increased in a dose-dependent manner.

Antitumor activity

All patients were evaluable for efficacy. In the MTD group (sunitinib $25 \mathrm{mg} /$ day, Schedule 2/2), 11/16 patients had 
Table 3 Treatment-emergent (all-causality) adverse events in $\geq 30 \%$ of patients in the maximum tolerated dose cohort (sunitinib $25 \mathrm{mg}$ /day on Schedule $2 / 2+$ cisplatin $+\mathrm{S}-1 ; n=16$ )

\begin{tabular}{lccc}
\hline Adverse event, $n(\%)$ & Grade 1/2 & Grade 3/4 & All grades \\
\hline Leukopenia & $4(25.0)$ & $12(75.0)$ & $16(100.0)$ \\
Neutropenia & $1(6.3)$ & $15(93.8)$ & $16(100.0)$ \\
Anemia & $6(37.5)$ & $9(56.3)$ & $15(93.8)$ \\
Decreased appetite & $14(87.5)$ & $1(6.3)$ & $15(93.8)$ \\
Thrombocytopenia & $9(56.3)$ & $6(37.5)$ & $15(93.8)$ \\
Fatigue & $14(87.5)$ & 0 & $14(87.5)$ \\
Nausea & $14(87.5)$ & 0 & $14(87.5)$ \\
Constipation & $12(75.0)$ & 0 & $12(75.0)$ \\
Stomatitis & $9(56.3)$ & 0 & $9(56.3)$ \\
Diarrhea & $7(43.8)$ & $1(6.3)$ & $8(50.0)$ \\
Dysgeusia & $7(43.8)$ & 0 & $7(43.8)$ \\
Pyrexia & $7(43.8)$ & 0 & $7(43.8)$ \\
Hiccups & $6(37.5)$ & 0 & $6(37.5)$ \\
Rash & $5(31.3)$ & 0 & $5(31.3)$ \\
Vomiting & $5(31.3)$ & 0 & $5(31.3)$ \\
\hline
\end{tabular}

Schedule $2 / 22$ weeks on treatment followed by 2 weeks off treatment

measurable disease. No patients had a complete response, and partial responses occurred in $6 / 11$ patients $(54.5 \%)$ with measurable disease, resulting in an overall objective response rate (ORR) of $37.5 \%$ (95\% confidence interval [CI], 15.2-64.6) in 16 evaluable patients. A further six patients experienced no disease progression for $\geq 24$ weeks, producing a CBR of $75.0 \%$ (95\% CI, 47.6-92.7) among the 16 patients. Maximum percentage reduction in target lesion size in the 11 patients with measurable disease is shown in Fig. 2. The CBR for patients treated at the MTD with scirrhous-type disease was $57.1 \%$ (95 \% CI, 18.490.1; 4/7 patients). Tumor response in one patient with scirrhous-type disease is shown in Fig. 3. At the MTD, median PFS was 12.5 months (95\% CI, 6.4-16.5) and 6month survival was $78.3 \%$ (95 \% CI, 56.5-100.0; Table 5; Fig. 4). Among the seven patients with scirrhous-type disease, four of five patients who had measurable lesion had a partial response, and median PFS was 12.5 months (95\% CI, 10.1-13.3).

\section{Discussion}

In this study, the MTD of sunitinib in combination with S-1 $(80-120 \mathrm{mg})$ plus cisplatin $60 \mathrm{mg} / \mathrm{m}^{2}$ was established as $25 \mathrm{mg}$ /day on Schedule 2/2 in patients with advanced or metastatic gastric cancer for whom curative therapy was not an option. Other tested combinations included sunitinib $25 \mathrm{mg} /$ day on a CDD schedule and a dose-increment from the MTD cohort to $37.5 \mathrm{mg}$; both cohorts were discontinued after DLTs were experienced. An additional 10 patients were then enrolled in the MTD cohort and followed for safety, antitumor activity, and PK parameters.

The MTD combination regimen demonstrated a manageable safety profile, with neutropenia and leukopenia as the most frequently reported grade 3 or 4 AEs: $93.8 \%$ and $75.0 \%$, respectively. This safety profile was also consistent with a similar phase I dose-escalation study conducted in Western patients with advanced gastric cancer [23]. In general, the type of AEs was consistent with those previously reported when 5-FU and cisplatin were administered in patients with gastric cancer [24], although the frequency of events, particularly hematologic AEs, was greater than expected from previous studies of sunitinib in other tumor types [18, 25-28]. Previously reported mild skin reactions associated with sunitinib, such as yellowing skin/discoloration [29], were not observed in this study. There were no grade 3 or 4 non-

Table 4 Pharmacokinetics in the maximum tolerated dose cohort (sunitinib $25 \mathrm{mg} /$ day on Schedule $2 / 2+$ cisplatin $+\mathrm{S}-1$ )

\begin{tabular}{|c|c|c|c|c|c|c|}
\hline \multirow[t]{2}{*}{ Treatment } & \multirow[t]{2}{*}{ Analyte } & \multirow[t]{2}{*}{$n$} & \multicolumn{2}{|c|}{ Mean $\mathrm{C}_{\max } \mathrm{ng} / \mathrm{mL}(\mathrm{CV} \%)$} & \multicolumn{2}{|c|}{ Mean $\mathrm{AUC}_{\text {last }} \mathrm{ng} \cdot \mathrm{h} / \mathrm{mL}(\mathrm{CV} \%)$} \\
\hline & & & Sunitinib alone or SP & Combined & Sunitinib alone or SP & Combined \\
\hline \multirow[t]{3}{*}{ Sunitinib } & Sunitinib & 7 & $15.8(32.2)$ & $16.2(44.6)$ & $234(25.3)$ & $244(38.6)$ \\
\hline & SU12662 & 7 & $2.9(43.6)$ & $2.8(49.3)$ & $46.0(34.2)$ & $50.5(50.7)$ \\
\hline & Total drug & 7 & $18.5(33.0)$ & $19.0(42.3)$ & $280(25.0)$ & $294(37.2)$ \\
\hline \multirow[t]{2}{*}{ S-1 } & Tegafur & 5 & $1,500(9.8)$ & $1,688(26.9)$ & $8,290(10.5)$ & $9,163(12.7)$ \\
\hline & $5-\mathrm{FU}$ & 5 & $144(23.5)$ & $114(16.5)$ & $582(19.3)$ & $522(28.0)$ \\
\hline \multirow[t]{2}{*}{ Cisplatin } & Total & 5 & $1,794(7.8)$ & $1,984(3.6)$ & $27,478(7.1)$ & $31,574(5.4)$ \\
\hline & Free & 5 & $178(68.3)$ & $187(74.6)$ & $790(25.8)$ & 973 (28.3) \\
\hline
\end{tabular}

$A U C_{\text {last }}$ area under the plasma concentration-time curve from time zero until last quantifiable observation; $C_{\max }$ maximum concentration; $C V$ coefficient of variation; 5-FU 5-fluorouracil; Schedule $2 / 22$ weeks on treatment followed by 2 weeks off treatment; $S P$ cisplatin $60 \mathrm{mg} / \mathrm{m}^{2}$ every 28 days + S-1 $40 \mathrm{mg} / \mathrm{m}^{2}$ twice daily every 3/1 weeks; SU12662 sunitinib active metabolite 
Fig. 2 Maximum percentage change in target lesion size in the maximum tolerated dose (MTD) cohort (sunitinib $25 \mathrm{mg}$ / day on Schedule 2/2+ cisplatin + S-1). ${ }^{\text {a }}$ Schedule $2 / 2$ 2 weeks on treatment followed by 2 weeks off treatment. ${ }^{a}$ Five of 16 patients receiving the MTD did not have measurable disease

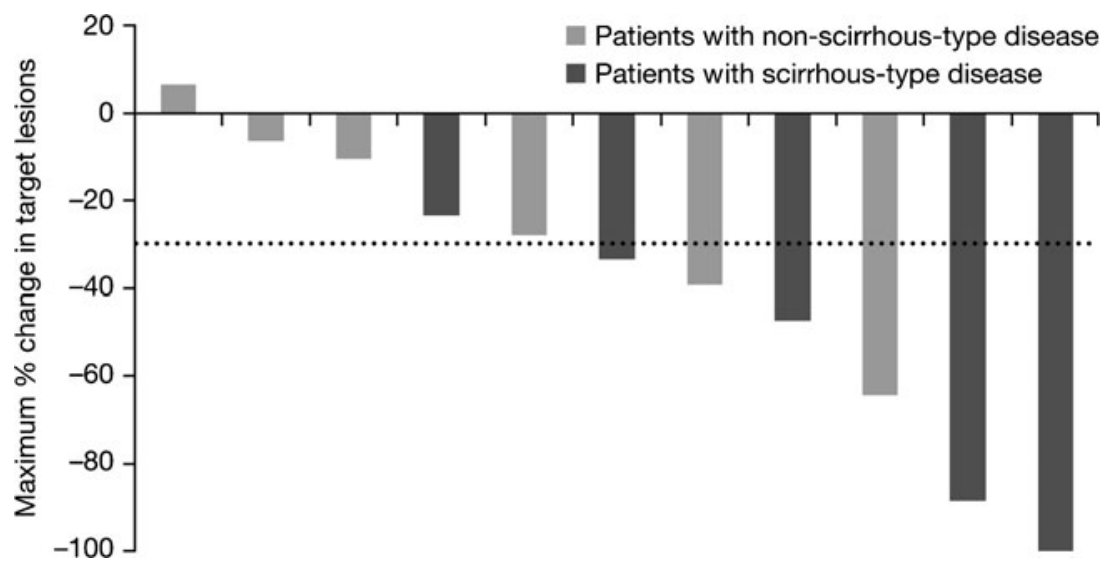

hematologic events reported in $\geq 30 \%$ of patients within the MTD cohort. No new safety signals were observed for sunitinib.

Although tumor evaluation was not the primary objective of this study, the ORR for the MTD cohort was $37.5 \%$ (95\% CI, 15.2-64.6) and included responses in patients with scirrhous-type disease. Since five of 16 patients treated at the MTD did not have measurable disease and were assessed as non-responders in the ORR calculation, tumor response rates may be underestimated in our study. The ORR at the MTD among the 11 patients with measurable disease was $54.5 \%$. Median PFS was 12.5 months (95\% CI, 6.4-16.5) in the overall MTD cohort. These results demonstrate promising preliminary antitumor activity, compared with that observed for sunitinib as a single-agent modality in advanced gastric cancer, [18] and with the median PFS of 6 months reported for S-1 plus cisplatin [30]. However, our results must be interpreted with caution given the limited sample size studied.

A multitargeted tyrosine kinase inhibitor like sunitinib may be a promising drug for scirrhous gastric cancer. Our preliminary results suggest that sunitinib in combination
Fig. 3 Tumor response in a patient with scirrhous gastric cancer who received the maximum tolerated dose of sunitinib $(25 \mathrm{mg} /$ day on Schedule 2/2) combined with cisplatin and S-1. Blue arrowheads: primary lesion; orange arrowheads: peritoneal metastasis; green arrowheads: lymph node metastasis; Schedule 2/2 2 weeks on treatment followed by 2 weeks off treatment
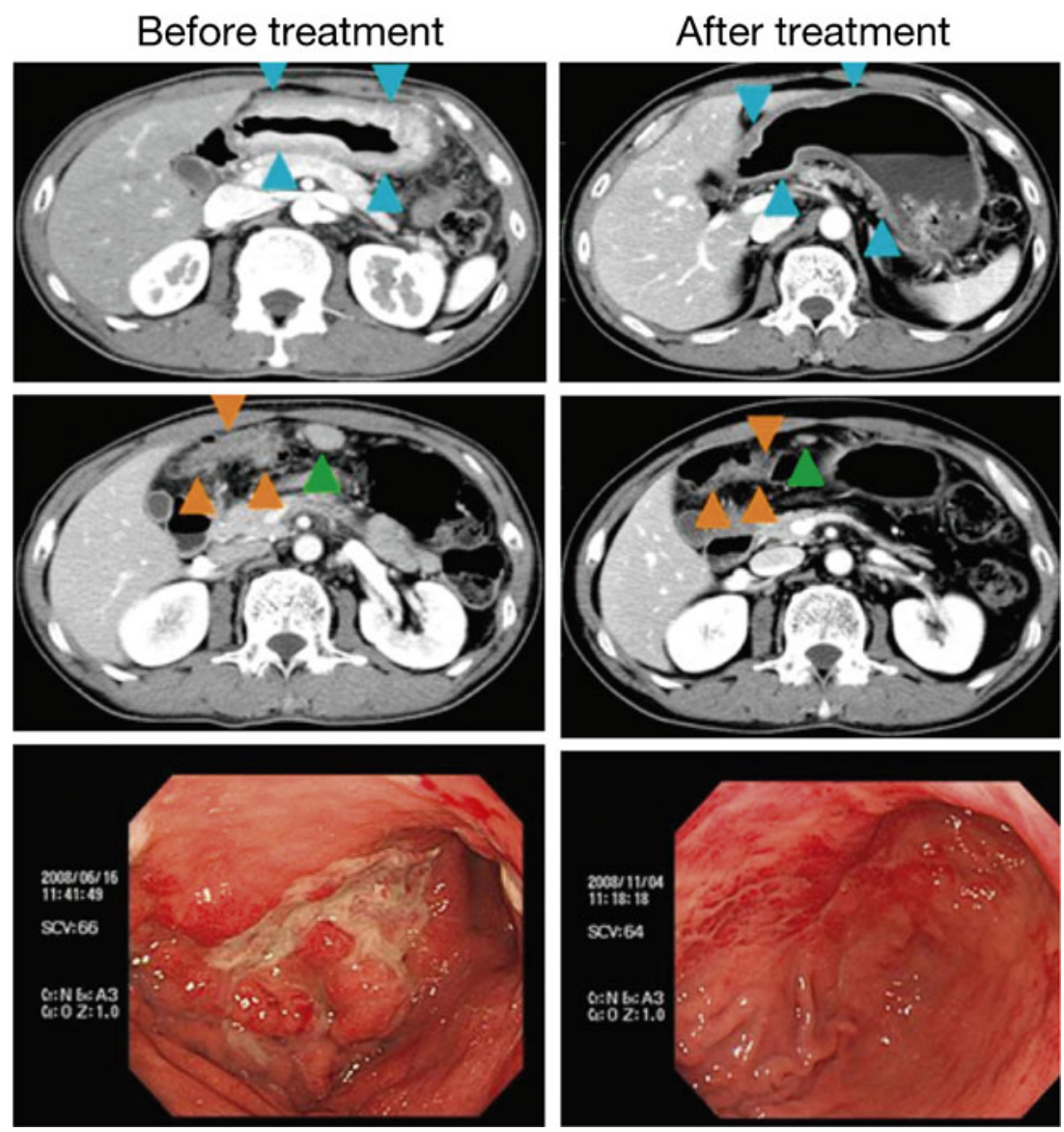
Table 5 Summary of progression-free survival

\begin{tabular}{|c|c|c|c|}
\hline & \multirow{2}{*}{$\begin{array}{l}\text { CDD schedule } \\
\text { Sunitinib } 25 \mathrm{mg} / \text { day }(n=4)\end{array}$} & \multicolumn{2}{|l|}{ Schedule $2 / 2$} \\
\hline & & Sunitinib $25 \mathrm{mg} /$ day $(n=16)^{\mathrm{a}}$ & Sunitinib $37.5 \mathrm{mg} /$ day $(n=6)$ \\
\hline Patients with events, $n(\%)$ & $2(50.0)$ & $9(56.3)$ & $4(66.7)$ \\
\hline \multicolumn{4}{|c|}{ Progression-free survival, months ${ }^{\mathrm{b}}$} \\
\hline Median & 7.1 & 12.5 & 5.8 \\
\hline $95 \% \mathrm{CI}$ & $6.7-7.5$ & $6.4-16.5$ & $4.4-7.9$ \\
\hline \multicolumn{4}{|c|}{ Probability of being event-free at month $6^{\mathrm{c}}$} \\
\hline Percentage & 100.0 & 78.3 & 50.0 \\
\hline $95 \% \mathrm{CI}^{\mathrm{d}}$ & $100.0-100.0$ & $56.5-100.0$ & $1.0-99.0$ \\
\hline \multicolumn{4}{|c|}{ Exploratory analysis: scirrhous-type disease } \\
\hline & & Schedule $2 / 2$ & \\
\hline & & Sunitinib $25 \mathrm{mg} /$ day $(n=7)^{\mathrm{a}}$ & \\
\hline Patients with events, $n(\%)$ & & $4(57.1)$ & \\
\hline \multicolumn{4}{|c|}{ Progression-free survival, months ${ }^{\mathrm{b}}$} \\
\hline Median & & 12.5 & \\
\hline $95 \%$ CI & & $10.1-13.3$ & \\
\hline
\end{tabular}

$C D D$ continuous daily dosing; $C I$ confidence interval; Schedule 2/2 2 weeks on treatment followed by 2 weeks off treatment

${ }^{\text {a }}$ Maximum tolerated dose

${ }^{\mathrm{b}}$ Based on the Brookmeyer and Crowley Method

${ }^{\mathrm{c}}$ Estimated from the Kaplan-Meier curve

${ }^{\mathrm{d}}$ Calculated from the product-limit method

with S-1 and cisplatin might have antitumor activity in patients with this disease type. However, as only seven of 16 patients at the MTD had scirrhous-type disease, caution should be used when interpreting these results. Despite this caveat, these data are encouraging, as scirrhous gastric cancer carries a worse prognosis than the non-scirrhous-type $[31,32]$, as it is characterized by rapid cancer cell infiltration and proliferation accompanied by extensive stromal fibrosis [32]. The proliferative and invasive ability of scirrhous gastric cancer cells have been shown to be closely associated with the growth factors produced by organ-specific

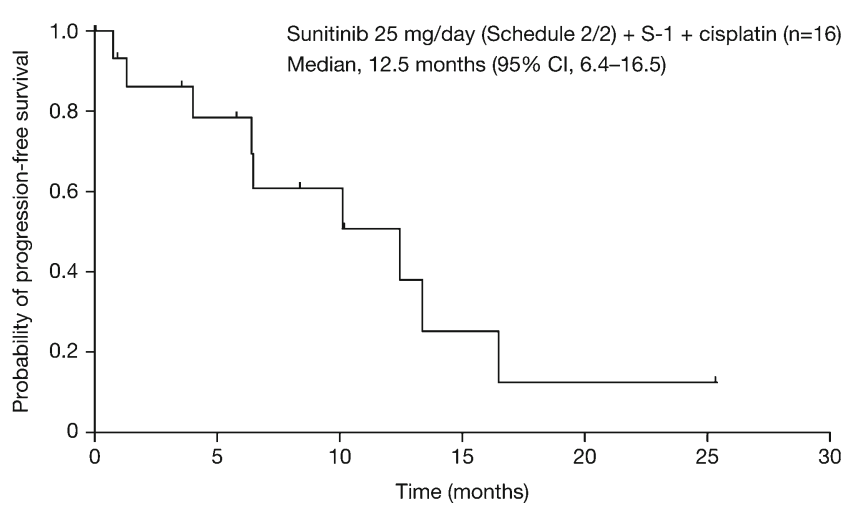

Fig. 4 Kaplan-Meier estimate of progression-free survival in the maximum tolerated dose cohort (sunitinib $25 \mathrm{mg}$ /day on Schedule $2 / 2+$ cisplatin $+\mathrm{S}-1$ ). $C I$ confidence interval; Schedule $2 / 22$ weeks on treatment followed by 2 weeks off treatment fibroblasts and other stromal cells [32]. Therefore, targeting this cancer-stroma interaction using a multitargeted tyrosine kinase inhibitor such as sunitinib could be a reasonable treatment option for patients with scirrhous gastric cancer. However, large randomized studies would be required to confirm this hypothesis.

The combination of sunitinib with cisplatin plus S-1 demonstrated no PK drug-drug interactions, consistent with the different pathways of metabolism and elimination for these drugs. These findings are consistent with those from the phase I study with cisplatin plus 5-FU in Western patients [23]. The mean observed $C_{\text {trough }}$ plasma concentration of $47.5 \mathrm{ng} / \mathrm{mL}$, for total drug (sunitinib plus SU12662) at steady-state with sunitinib $25 \mathrm{mg} /$ day dosing, in the present study suggests that optimal sunitinib exposure was almost achieved, in terms of the required concentration for target inhibition of $\geq 50 \mathrm{ng} / \mathrm{mL}$ [16].

In summary, the MTD of sunitinib was $25 \mathrm{mg} /$ day on Schedule $2 / 2$ in combination with cisplatin and S-1 when administered as a first-line therapy in patients with advanced or metastatic gastric cancer. This combination had a manageable safety profile and showed preliminary evidence of antitumor activity.

Acknowledgments We thank the participating patients and their families, as well as the investigators, research nurses, study coordinators, and operations staff. Medical writing support was provided by 
Nicola Crofts and Molly Heitz (ACUMED ${ }^{\circledR}$, Tytherington, UK) with funding from Pfizer Inc.

Conflict of interest Narikazu Boku, Nozomu Machida, Kei Muro, and Yoshinori Miyata have nothing to disclose.

Mariajose Lechuga and Nobuyuki Kimura are Pfizer Inc. employees and hold Pfizer Inc. stock.

Satoshi Hashigaki and Mie Suzuki are Pfizer Inc. employees.

Funding source This study was sponsored by Pfizer Inc.

\section{Quantity of supporting information None}

Open Access This article is distributed under the terms of the Creative Commons Attribution License which permits any use, distribution, and reproduction in any medium, provided the original author(s) and the source are credited.

\section{References}

1. Jemal A, Bray F, Center MM, Ferlay J, Ward E, Forman D (2011) Global cancer statistics. CA Cancer J Clin 61:69-90

2. Inoue M, Tsugane $S$ (2005) Epidemiology of gastric cancer in Japan. Postgrad Med J 81:419-424

3. Ajani JA (2007) Recent developments in cytotoxic therapy for advanced gastric or gastroesophageal carcinoma: the phase III trials. Gastrointest Cancer Res 1:S16-S21

4. Ajani JA, Barthel JS, Bekaii-Saab T, Bentrem DJ, D'Amico TA, Das P, Denlinger C, Fuchs CS, Gerdes H, Hayman JA, Hazard L, Hofstetter WL, Ilson DH, Keswani RN, Kleinberg LR, Korn M, Meredith K, Mulcahy MF, Orringer MB, Osarogiagbon RU, Posey JA, Sasson AR, Scott WJ, Shibata S, Strong VE, Washington MK, Willett C, Wood DE, Wright CD, Yang G (2010) Gastric cancer. J Natl Compr Canc Netw 8:378-409

5. Catalano V, Labianca R, Beretta GD, Gatta G, De BF, Van CE (2009) Gastric cancer. Crit Rev Oncol Hematol 71:127-164

6. Bang YJ, Van CE, Feyereislova A, Chung HC, Shen L, Sawaki A, Lordick F, Ohtsu A, Omuro Y, Satoh T, Aprile G, Kulikov E, Hill J, Lehle M, Ruschoff J, Kang YK (2010) Trastuzumab in combination with chemotherapy versus chemotherapy alone for treatment of HER2-positive advanced gastric or gastro-oesophageal junction cancer (ToGA): a phase 3, open-label, randomised controlled trial. Lancet 376:687-697

7. Glimelius B, Ekstrom K, Hoffman K, Graf W, Sjoden PO, Haglund U, Svensson C, Enander LK, Linne T, Sellstrom H, Heuman R (1997) Randomized comparison between chemotherapy plus best supportive care with best supportive care in advanced gastric cancer. Ann Oncol 8:163-168

8. Wagner AD, Grothe W, Haerting J, Kleber G, Grothey A, Fleig WE (2006) Chemotherapy in advanced gastric cancer: a systematic review and meta-analysis based on aggregate data. J Clin Oncol 24:2903-2909

9. Drescher D, Moehler M, Gockel I, Frerichs K, Muller A, Dunschede F, Borschitz T, Biesterfeld S, Holtmann M, Wehler T, Teufel A, Herzer K, Fischer T, Berger MR, Junginger T, Galle PR, Schimanski CC (2007) Coexpression of receptor-tyrosine-kinases in gastric adenocarcinoma-a rationale for a molecular targeting strategy? World J Gastroenterol 13:3605-3609

10. Zhang H, Wu J, Meng L, Shou CC (2002) Expression of vascular endothelial growth factor and its receptors KDR and Flt-1 in gastric cancer cells. World J Gastroenterol 8:994-998
11. Hassan S, Kinoshita Y, Kawanami C, Kishi K, Matsushima Y, Ohashi A, Funasaka Y, Okada A, Maekawa T, He-Yao W, Chiba T (1998) Expression of protooncogene c-kit and its ligand stem cell factor (SCF) in gastric carcinoma cell lines. Dig Dis Sci 43:8-14

12. Katano M, Nakamura M, Fujimoto K, Miyazaki K, Morisaki T (1998) Prognostic value of platelet-derived growth factor-A (PDGF-A) in gastric carcinoma. Ann Surg 227:365-371

13. Muller-Tidow C, Schwable J, Steffen B, Tidow N, Brandt B, Becker K, Schulze-Bahr E, Halfter H, Vogt U, Metzger R, Schneider PM, Buchner T, Brandts C, Berdel WE, Serve H (2004) High-throughput analysis of genome-wide receptor tyrosine kinase expression in human cancers identifies potential novel drug targets. Clin Cancer Res 10:1241-1249

14. Wagner AD, Moehler M (2009) Development of targeted therapies in advanced gastric cancer: promising exploratory steps in a new era. Curr Opin Oncol 21:381-385

15. Abrams TJ, Lee LB, Murray LJ, Pryer NK, Cherrington JM (2003) SU11248 inhibits KIT and platelet-derived growth factor receptor beta in preclinical models of human small cell lung cancer. Mol Cancer Ther 2:471-478

16. Mendel DB, Laird AD, Xin X, Louie SG, Christensen JG, Li G, Schreck RE, Abrams TJ, Ngai TJ, Lee LB, Murray LJ, Carver J, Chan E, Moss KG, Haznedar JO, Sukbuntherng J, Blake RA, Sun L, Tang C, Miller T, Shirazian S, McMahon G, Cherrington JM (2003) In vivo antitumor activity of SU11248, a novel tyrosine kinase inhibitor targeting vascular endothelial growth factor and plateletderived growth factor receptors: determination of a pharmacokinetic/ pharmacodynamic relationship. Clin Cancer Res 9:327-337

17. O'Farrell AM, Abrams TJ, Yuen HA, Ngai TJ, Louie SG, Yee KW, Wong LM, Hong W, Lee LB, Town A, Smolich BD, Manning WC, Murray LJ, Heinrich MC, Cherrington JM (2003) SU11248 is a novel FLT3 tyrosine kinase inhibitor with potent activity in vitro and in vivo. Blood 101:3597-3605

18. Bang YJ, Kang YK, Kang WK, Boku N, Chung HC, Chen JS, Doi T, Sun Y, Shen L, Qin S, Ng WT, Tursi JM, Lechuga MJ, Lu DR, RuizGarcia A, Sobrero A (2010) Phase II study of sunitinib as second-line treatment for advanced gastric cancer. Invest New Drugs

19. Abrams TJ, Murray LJ, Pesenti E, Holway VW, Colombo T, Lee LB, Cherrington JM, Pryer NK (2003) Preclinical evaluation of the tyrosine kinase inhibitor SU11248 as a single agent and in combination with "standard of care" therapeutic agents for the treatment of breast cancer. Mol Cancer Ther 2:1011-1021

20. Yoon YK, Im SA, Min A, Kim HP, Hur HS, Lee KH, Han SW, Song SH, Youn OD, Kim TY, Kim WH, Bang YJ (2012) Sunitinib synergizes the antitumor effect of cisplatin via modulation of ERCC1 expression in models of gastric cancer. Cancer Lett 321:128-136

21. Lenz HJ, Lee FC, Haller DG, Singh D, Benson AB III, Strumberg D, Yanagihara R, Yao JC, Phan AT, Ajani JA (2007) Extended safety and efficacy data on S-1 plus cisplatin in patients with untreated, advanced gastric carcinoma in a multicenter phase II study. Cancer 109:33-40

22. Therasse P, Arbuck SG, Eisenhauer EA, Wanders J, Kaplan RS, Rubinstein L, Verweij J, Van Glabbeke M, van Oosterom AT, Christian MC, Gwyther SG (2000) New guidelines to evaluate the response to treatment in solid tumors. J Natl Cancer Inst 92:205-216

23. Gomez-Martin C, Gil-Martin M, Montagut C, Nunez JA, Salazar M, Puig R, Khosravan R, Tursi JM, Lechuga MJ, Bellmunt J (2010) A phase I, dose-finding study of sunitinib in combination with cisplatin and 5-fluorouracil in patients with advanced gastric cancer. Ann Oncol 21(Supplement 8):818P, abstr

24. Kang YK, Kang WK, Shin DB, Chen J, Xiong J, Wang J, Lichinitser M, Guan Z, Khasanov R, Zheng L, Philco-Salas M, Suarez T, Santamaria J, Forster G, McCloud PI (2009) Capecitabine/cisplatin versus 5 -fluorouracil/cisplatin as first-line therapy in patients with advanced gastric cancer: a randomised phase III noninferiority trial. Ann Oncol 20:666-673 
25. Burstein HJ, Elias AD, Rugo HS, Cobleigh MA, Wolff AC, Eisenberg PD, Lehman M, Adams BJ, Bello CL, DePrimo SE, Baum CM, Miller KD (2008) Phase II study of sunitinib malate, an oral multitargeted tyrosine kinase inhibitor, in patients with metastatic breast cancer previously treated with an anthracycline and a taxane. J Clin Oncol 26:1810-1816

26. Demetri DG, van Oosterom A, Garrett CR, Blackstein ME, Shah MH, Verweij J, McArthur G, Judson IR, Heinrich MC, Morgan JA, Desai J, Fletcher CD, George S, Bello CL, Huang X, Baum CM, Casali PG (2006) Efficacy and safety of sunitinib malate in patients with advanced gastrointestinal stromal tumor following failure of imatinib mesylate due to resistance or intolerance. N Engl J Med submitted

27. Motzer RJ, Hutson TE, Tomczak P, Michaelson MD, Bukowski RM, Rixe O, Oudard S, Negrier S, Szczylik C, Kim ST, Chen I, Bycott PW, Baum CM, Figlin RA (2007) Sunitinib versus interferon alfa in metastatic renal-cell carcinoma. N Engl J Med 356:115-124

28. Socinski MA, Novello S, Brahmer JR, Rosell R, Sanchez JM, Belani CP, Govindan R, Atkins JN, Gillenwater HH, Pallares C, Tye L, Selaru P, Chao RC, Scagliotti GV (2008) Multicenter, phase
II trial of sunitinib in previously treated, advanced non-small-cell lung cancer. J Clin Oncol 26:650-656

29. Faivre S, Delbaldo C, Vera K, Robert C, Lozahic S, Lassau N, Bello C, DePrimo S, Brega N, Massimini G, Armand JP, Scigalla P, Raymond E (2006) Safety, pharmacokinetic, and antitumor activity of SU11248, a novel oral multitarget tyrosine kinase inhibitor, in patients with cancer. J Clin Oncol 24:25-35

30. Koizumi W, Narahara H, Hara T, Takagane A, Akiya T, Takagi M, Miyashita K, Nishizaki T, Kobayashi O, Takiyama W, Toh Y, Nagaie T, Takagi S, Yamamura Y, Yanaoka K, Orita H, Takeuchi M (2008) S-1 plus cisplatin versus S-1 alone for first-line treatment of advanced gastric cancer (SPIRITS trial): a phase III trial. Lancet Oncol 9:215-221

31. Yoshida M, Ohtsu A, Boku N, Miyata Y, Shirao K, Shimada Y, Hyodo I, Koizumi W, Kurihara M, Yoshida S, Yamamoto S (2004) Long-term survival and prognostic factors in patients with metastatic gastric cancers treated with chemotherapy in the Japan Clinical Oncology Group (JCOG) study. Jpn J Clin Oncol 34:654-659

32. Yashiro M, Hirakawa K (2010) Cancer-stromal interactions in scirrhous gastric carcinoma. Cancer Microenviron 3:127-135 